\title{
FOOD AND FEEDING HABIT OF CYPRINUS CARPIO VAR. SPECULARIS
}

\author{
M R Manon ${ }^{1}$ and M D Hossain ${ }^{2}$
}

\begin{abstract}
The study was carried out from November 2010 to August 2011. A total of 137 specimens of Cyprinus carpio var. specularis were collected from Naogaon municipal fish market, Shabi hat fish market, Niamatpur fish market and directly from the culture pond of Naogaon district The month-wise collection and experiments were made to show the seasonal variation in food choice, and feeding habit of the fish. The highest percentage of empty stomach was in the month of April 2011 (56.67\%) and the lowest percentage of empty stomach was in the month of August 2011 (26.32\%). The highest percentage of full stomachs was found in the month of August 2011 (73.68\%) and the lowest percentage of full stomachs was found in April 2011 (43.33\%). The analysis of stomach contents of C. carpio var. specularis revealed that the food of the fish consists of aquatic plant parts (20.12\%), phytoplankton (16.46\%), zooplankton (19.69\%), debris and detritus (22.00\%), insects (6.78\%) and semi-digested materials (14.83\%). The highest percentage $(33.26 \%)$ of aquatic plant parts were observed in June 2011 and the lowest percentage (8.80\%) in December 2010. The average total length was $37.83 \pm 6.96 \mathrm{~cm}$ and the average alimentary canal length was $100.63 \pm 7.89 \mathrm{~cm}$.
\end{abstract}

Keywords: Food and feeding habit, Cyprinus carpio var. specularis, alimentary canal

\section{INTRODUCTION}

Food and feeding habit of fish are important biological factors for selecting a group of fish for culture in ponds to avoid competition for food among themselves and live in association and to utilize all the available food (Dewan and Saha, 1979). It is virtually impossible to gather sufficient information of food and feeding habit of fish in their natural habitat without studying its gut contents. A through knowledge on the food and feeding habit of fishes provide keys for the selection of culturable species and the importance of much information is necessary for successful fish farming. The food habit of different fish varies from month to month. This variation is due to changes in the composition of food organisms occurring at different seasons of the year. Studies on the food and feeding habit of different fishes have been made by many workers like Moffet and Hunt (1943), Khan (1947), Hynes (1950). Karim and Hossain (1972), Doha (1974), Dewan and Saha (1979), Jhingran (1983), Bhuiyan and Haque (1984), Bhuiyan and Islam (1990, 1991), Hossain et al. (1991), Bhuiyan et al. (1997, 1998, 1999) and others. Jhingran (1983) stated that the natural food of fishes are classified under three groups (i) Main food (ii) Occasional food and (iii) Emergency food. The stimuli to food are of two kinds: (a) factors affecting the internal motivation or drive for feeding, including season, time of day, light intensity, lime and nature of last feeding, temperature and any internal rhythm that may exists;

\footnotetext{
${ }^{1}$ Lecturer (Zoology), Niamotpur Degree College, Naogaon.

${ }^{2}$ Associate Professor, Department of Fisheries, University of Rajshahi.
} 
(b) food stimuli perceived by the sense like smell, taste, sight and the lateral line system that release and control the momentary feeding act.

The knowledge of food and feeding habit helps to select such species of fish for culture and produce an optimum yield by utilizing all the available potential food of the water bodies without any competition. The present study deals with the food mid feeding habit of $C$. carpio var. specularis, observe the stomach contents and the relationship between total length and alimentary canal length.

\section{MATERIALS AND METHODS}

A total of 137 specimens of C. carpio var. specularis were collected from November 2010 to August 2011. The month-wise collection and experiments were made to show the seasonal variation in food choice, and feeding habit of the fish. Just after collection $10 \%$ formalin solution was injected into the gut of all the fishes in order to stop digestion of food items. All the experiments were carried out in the laboratory of the Dept. of Fisheries, University of Rajshahi, Some fresh and live specimens were also examined.

The stomach of the fishes were dissected with the help of a simple scissors and the stomach contents were taken into a petridish and the food items were identified by (Magnification 5X, 10X) and weighted in an electronic balance. Gravimetric method (Hynes, 1950; Pillay, 1954) was followed for estimation of the percentage composition of food items.

The relationship between total length and the alimentary canal length and total length and stomach length the well known statistical formula was-

$$
\mathrm{Y}=\mathrm{a}+\mathrm{bX}
$$

Where,

$\mathrm{Y}=$ alimentary canal length (ACL), $\mathrm{X}=$ Total length (TL), ' $\mathrm{a}$ ' is the interception on the ordinate and ' $b$ ' is the regression co-efficient.

\section{RESULTS AND DISCUSSION}

\section{Seasonal feeding intensity}

The results of the analysis of 137 stomachs of the fishes have been presented in the Table 1 and 2 which is shown fullness of stomach of C. carpio var. specularis. Out of the 137 stomachs examined 61.88\% contained food and the rest $38.22 \%$ were without food, which varied from months to month. Among these 16 were full, 24 were $3 / 4$ full, 21 were $1 / 2$ full, 21 were $1 / 4$ full and 17 were empty. The highest percentage of empty stomach was in the month of April 2011 (56.67\%) and the lowest percentage of empty stomach was in the month of August 2011 (26.32\%). The highest percentage of full stomachs was found in the month of August 2011 (73.68\%) and the lowest percentage of full stomachs was found in April 2011 (43.33\%) (Table 1).

The maximum number of 3/4 full stomachs was observed in February 2011 and the minimum number of $3 / 4$ full stomachs was recorded in the month of December, 2010. The condition of feed was also related to maturity of fish. Immature fishes were found to feed with almost equal intensity throughout the year. These findings clearly indicated that the feeding intensity of juvenile fishes is increased. The rate of feeding activity based on monthly variation was also recorded by Moffet and Hunt (1943) and Khan (1947) in their study on blue gill and Labeo rohita respectively. Studies on the food and feeding 
habits have been made by many workers like, Hynes (1950), Mustafa et al. (1981), Bhuiyan et al. $(1997,1998,1999)$ etc.

Table-1: $\quad$ Season and feeding activity of Cyprinus carpio var. specularis (based on number of fish, percentage of fullness and emptiness)

\begin{tabular}{|c|c|c|c|c|}
\hline \multirow{4}{*}{ Year } & Months & $\begin{array}{c}\text { Number of } \\
\text { fishes examined }\end{array}$ & $\begin{array}{c}\text { Percentage of } \\
\text { fullness }\end{array}$ & $\begin{array}{c}\text { Percentage of } \\
\text { emptiness }\end{array}$ \\
\hline \multirow{3}{*}{2010} & Nov & 18 & 72.56 & 27.44 \\
\cline { 2 - 5 } & Dec & 16 & 59.16 & 40.84 \\
\hline \multirow{3}{*}{2011} & Jan & 20 & 68.27 & 31.73 \\
\cline { 2 - 5 } & Feb & 13 & 69.88 & 30.12 \\
\cline { 2 - 5 } & Mar & 14 & 65.00 & 35.00 \\
\cline { 2 - 5 } & Apr & 10 & 43.33 & 56.67 \\
\cline { 2 - 5 } & May & 12 & 64.77 & 36.23 \\
\cline { 2 - 5 } & Jun & 10 & 56.14 & 43.86 \\
\cline { 2 - 5 } & Jul & 16 & 46.00 & 54.00 \\
\hline \multirow{2}{*}{ Mean \pm Sd } & Aug & 08 & 73.68 & 26.32 \\
\hline
\end{tabular}

N. B: Fullness includes full, $3 / 4$ full and $1 / 2$ full stomachs. Emptiness includes $1 / 4$ full and empty stomachs

\section{Seasonal patterns of feeding based on percentage occurrence of food items}

The findings of the study shown that the food items of C. carpio var. specularis consists of aquatic plant parts, phytoplankton, zooplankton, debris and detritus, insects and semi-digested food materials. The analysis of stomach contents of $C$. carpio var. specularis revealed that the food of the fish consists of aquatic plant parts (20.12\%), phytoplankton (16.46\%), zooplankton (19.69\%), debris and detritus (22.00\%), insects (6.78\%) and semi-digested materials (14.83\%). The highest percentage (33.26\%) of aquatic plant parts were observed in June 2011 and the lowest percentage (8.80\%) in December 2010. The highest percentage (25.36\%) of phytoplankton was observed in January 2011 and the lowest percentage (10.13\%) in June 2011. The highest percentage (26.29\%) of zooplankton was observed in April 2011 and the lowest percentage (12.28\%) in December 2010. The highest percentage (31.27\%) of debris and detritus was observed in November 2010 and the lowest percentage (14.22\%) in April 20011. The highest percentage (9.51\%) of insects was found in December 2010 and the lowest percentage (4.0\%) in June 2011. The highest percentage (35.61\%) of semi-digested materials was found in December 2010 and the lowest percentage (6.46\%) in June 2011 (Table 2 and Fig. 1). Debris and detritus parts were very dominant food item of C. carpio var. specularis. Joadder and Hossain (2008) reported that the crustaceans and molluscs were very dominant food items in C. carpio var. specularis throughout the year. 
Table-2: Percentage of major food items found in the stomach of different size of Cyprinu carpio var. specularis

\begin{tabular}{|c|c|c|c|}
\hline \multirow[b]{2}{*}{ Food items } & \multicolumn{3}{|c|}{ Size of the fish } \\
\hline & $\begin{array}{l}\text { Young } \\
(8-16 \mathrm{~cm})\end{array}$ & $\begin{array}{l}\text { Juvenile } \\
(17-29 \mathrm{~cm})\end{array}$ & $\begin{array}{l}\text { Adult } \\
(30-90 \mathrm{~cm})\end{array}$ \\
\hline Phytoplankton & 13.78 & 5.53 & 5.31 \\
\hline Algae & 18.33 & 11.38 & 12.05 \\
\hline Aquatic plant materials & 7.18 & 10.25 & 12.36 \\
\hline Zooplankton & 10.12 & 1.74 & 2.33 \\
\hline Protozoans & 8.20 & 8.20 & 11.26 \\
\hline Crustaceans & 5.30 & 6.17 & 7.13 \\
\hline Insects & 3.07 & 2.98 & 2.76 \\
\hline Molluscans & 14.37 & 4.92 & 5.42 \\
\hline Debris and detritus & 18.35 & 27.36 & 28.05 \\
\hline Sand and muds & 1.30 & 22.48 & 13.33 \\
\hline
\end{tabular}

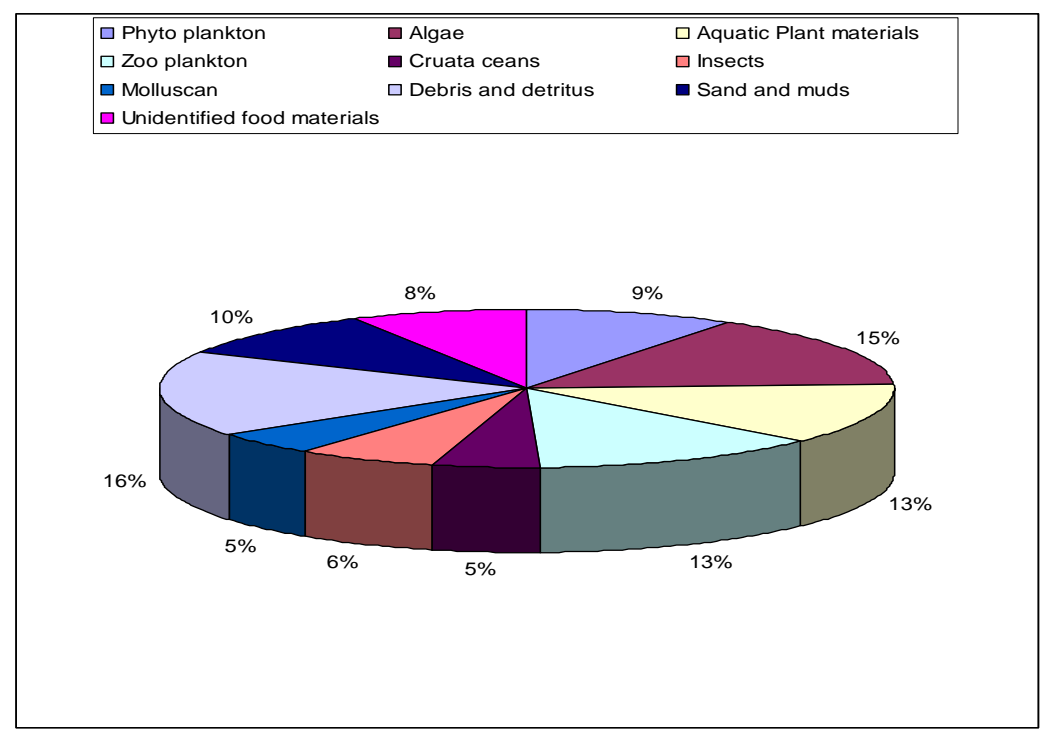

Fig. 1. Percentage occurrence of different food items of Cyprinus carpio var. specularis

\section{Total length and alimentary canal length relationship}

The alimentary canal length was larger than the total length. The average total length was $37.83 \pm 6.96$ $\mathrm{cm}$ and the average alimentary canal length was $100.63 \pm 7.89 \mathrm{~cm}$ (Table-3). The ratio of total length and alimentary canal length was 1: 2.66. Total length (TL) and alimentary canal length (ACL) of Cyprinus carpio var. specularis were positively correlated (Table-4). The regression equation was obtained as in total length and alimentary canal length, ACL $=19.709+2.1393$ TL and the coefficient of correlation, $r=0.853$ (Fig. 2).

Mathematical relationship between total length (TL) and alimentary canal length (ACL) was established and shown positive linear relationship. It was observed that the alimentary canal length is larger than the total length. It was recorded that the total length of various size groups was 
$37.83 \pm 6.96 \mathrm{~cm}$ in average and the alimentary canal length of various size groups were $100.63 \pm 7.89$ in average. The ratio of body length and alimentary canal length was recorded as $1: 2.66$. The value of co-efficient of correlation, $r=0.853$ which indicates that there is positive correlation between the variables. Joadder (2006) reported that the TL and ACL ratio of Gagata youssoufi was 1: 0.97, the calculated regression equation was ACL $=-2.1161+0.5841 \mathrm{TL}(\mathrm{r}=0.966)$.

Table 3: The mean Total length (TL) and Alimentary canal length (ACL) ratio of the Cyprinus carpio var. specularis

\begin{tabular}{|l|c|c|c|}
\hline No. of examined fish & Mean ACL cm & Mean TL & TL:ACL \\
\hline 42 & 94.23 & 35.19 & $1: 2.68$ \\
\hline 38 & 97.86 & 36.12 & $1: 2.71$ \\
\hline 39 & 99.72 & 39.47 & $1: 2.53$ \\
\hline 40 & 103.20 & 38.26 & $1: 2.70$ \\
\hline 41 & 108.16 & 40.10 & $1: 2.70$ \\
\hline Mean \pm SD & $\mathbf{1 0 0 . 6 3} \pm \mathbf{7 . 8 9}$ & $\mathbf{3 7 . 8 3} \pm \mathbf{6 . 9 6}$ & $\mathbf{1 : 2 . 6 6}$ \\
\hline
\end{tabular}

Table-4: The value of constant intercept "a" regression co-efficient "b" co-efficient of correlation " $r$ " the ratio of ACL and TL of Cyprinus carpio var. specularis

\begin{tabular}{|l|l|l|l|l|}
\hline \multicolumn{2}{|l|}{ Relationship } & Values of & Values of \\
"a" & Values of \\
Ordinance(Y) & Abscissa(X) & r" \\
\hline Total length & Alimentary canal length & 19.709 & 2.1393 & 0.853 \\
\hline
\end{tabular}

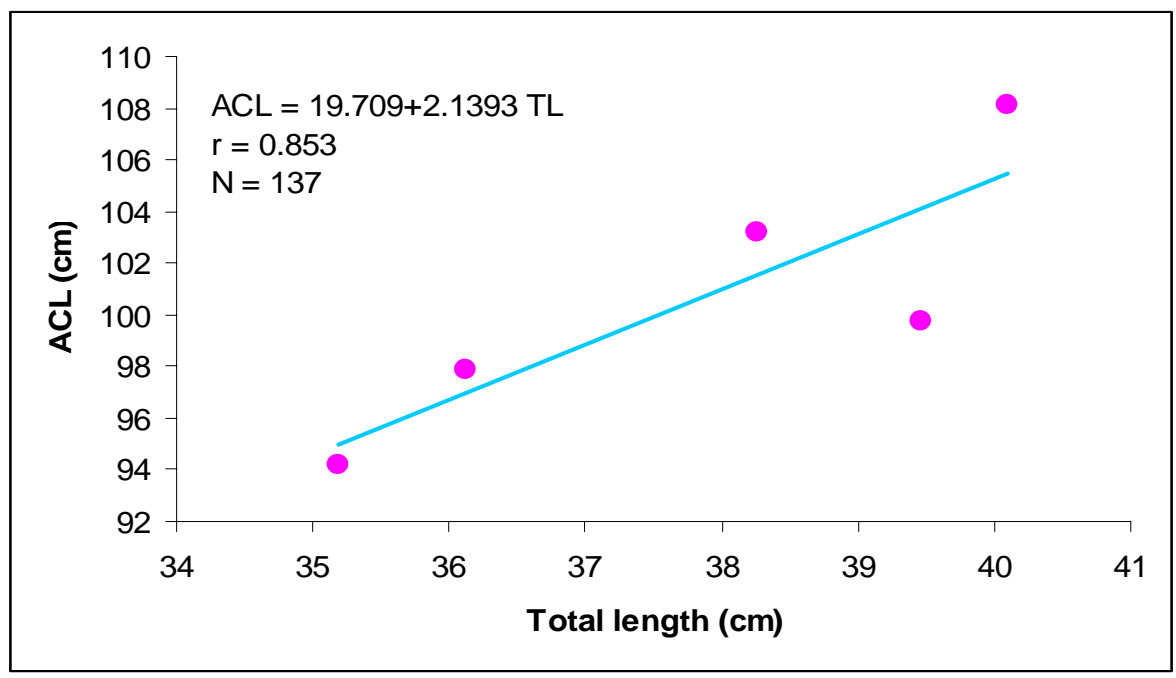

Fig. 2: $\quad$ Relationship between total length (TL) and alimentary canal length (ACL) of Cyprinus carpio var. specularis

\section{Food habit}

The food items of C. carpio var. specularis were classified into 6 groups. C. carpio var. specularis is mostly omnivorous in nature. Among the food items zooplankton and debris and detritus were most 
dominant followed by the aquatic plant parts, phytoplankton, zooplankton, debris and detritus, insects and semi-digested food materials. In this case the nature of this fish is omnivorous because also feeds on zooplankton in culture ponds.

It was observed that the feeding intensity of C. carpio var. specularis in matured fish was poor and the feeding intensity was very poor in spawning period. The feeding intensity of immature fishes was found to feed actively. The food and feeding habits of fishes vary from month to month. This variation is due to the changes in the composition of food organisms occurring at different seasons of the year (Bhuiyan et al., 1997, 1998, 1999).

\section{REFERENCES}

Bhuiyan, A. S. and Haque, M. S. 1984. Studies on the seasonal changes of food habit of Mystus vittatus (Bloch) (Bagridae : Cypriniformes). Proc. $4^{\text {th }}$. Nat. Zool. Conf. Bangladesh. 88-91.

Bhuiyan, A. S. and Islam, M. N. 1990. Seasonal variation in the percentage composition of the food of Xenentodon cancila. Univ. J. Zool. Rajshahi Univ. 7: 33-34.

Bhuiyan, A. S. and Islam, M. N. 1991. Observation on the food and feeding habit of Ompok pabda (Ham.) from the river Padma (Siluridae : Cypriniformes). Pakistan J. Zool. 23(1): 75-77.

Bhuiyan, A. S., Begum, M. and Nessa, Q. 1997. Observation of the food and feeding habit of Clupisoma atherinoides (Bloch) (Siluriformes: Schilbidae). Univ. j. zool. Rajshahi Univ., 16: 1-5.

Bhuiyan, A. S., Nessa, Q. and Begum, M. 1998. The food and feeding habit of Puntius gonionotus (Bleeker) (Cyprinidae: Cypriniformes). Bangladesh J. Zool., 26 (1): 73-78.

Bhuiyan, A. S., Nessa, Q. and Hossain, M. D. 1999. Seasonal pattern of feeding of grey mullet, Mugil cephalus (L.) (Mugiliformes : Mugilidae). Pakistan J. Zool. 31(1): 295-297.

Dewan, S. and Shaha, S. N. 1979. Food and feeding habits of Tilapia nilotica (L.) (Perciformes : Cichlidae). II. Diel and seasonal patterns of feeding. Bangladesh J. Zool. 7(2): 75-80.

Doha, S. 1974. Investigation into the biology of the goby Glossogobius giuris (Ham.-Buch.) (Perciformes:Gobidae). Bangladesh J. Zool. 2(2): 95-106.

Hossain, M. A., Rahman, M. H. and Parween, S. 1991. Notes on the length-weight relationship of Lepidocephalus guntea. Bangladesh J. Zool. 19(1): 145-146.

Hynes, H. B. N. 1950. The food of freshwater sticklebacks (Gasterosteus aculeatus and Pygosteus pungitius) with a review of methods used in studies of the food of fishes. J. Anim. Ecol., 19: 26-28.

Jhingran, V. G. 1983. Fish and Fisheries of India (Revised and enlarged $2^{\text {nd }}$ ed). Hindustan Publishing Corporation (India) Delhi. 645 pp. 
Joadder, A. R. and Hossain, M. D. 2008. Observation on the food and feeding habit of Cyprinus carpio var. communis (Linnaeus) (Cypriniformes: Cyprinidae). J. Sci. Foundation, 6(2): 95-99.

Joadder, A. R. M. 2006. Food and feeding habits of Gagata youssoufi (Rahman) from the river Padma in Rajshahi. Univ. J. Zool. Rajshahi Univ. 25: 69-71.

Karim, M. A. and Hossain, A. 1972. Studies on the biology of Mastacembelus pancalus (spiny eel) in artificial pond. Part -II. Sexual maturity and fecundity. Bangladesh J. Biol. and Agril. Sci. 1(2): 15-18.

Khan, H. 1947. Development of fisheries in the Punjab. III. Culture and propagation of indigenous species of fish. Indian Farming. 8(9): 147-153.

Moffet, J. W. and Hunt, B. P. 1943. Winter breeding habits of blue gills, Leponis machrochirus (Refinesque), yellow perch, Perca flavescens (Mirchill) in cedar like westenow country, Michigan. Trans. Amer. Fish. Soc. 73: 232-22.

Mustafa, G., Islam, K. R. and Ali, S. 1981. Seasonal patterns of feeding of the freshwater fish Colisa fasciata (Bloch). Ibd. 9(1) : 49-50.

Pillay, T. V. R. 1954. The biology of the grey mullet (Mugil cephalus L.) . Proc. Nat. Inst. Sci. India. 20 (2) : 18- 217. 